\title{
AIDS research turned upside down
}

Two recent developments support the view that HIV is a necessary but not sufficient cause of AIDS: if confirmed, they must cause a benign revolution in the search for better treatment and for prophylaxis.

Professor Peter Duesberg from the University of California at Berkeley is probably sleeping more easily at night now than for five years, since he first took up cudgels against the doctrine that AIDS is caused by the retrovirus HIV (or human immunodeficiency virus). Duesberg has been pilloried for his heterodox views (best put in Proc.USNat.Acad.Sci.U.S.A. 88, 1575; February 1991), and faced with the threat that his research funds would be snatched away. Now there some evidence to support his long fight against the establishment (among which, sadly, he counts this journal).

The evidence comes in two mutually consistent parts. Earlier this month, Tracy A. Kion and Geoffrey W. Hoffmann from the University of British Columbia published an account of experiments in which mice that had been treated with T lymphocytes from another mouse strain, but not exposed to HIV in any form, had been found to generate antibodies against two of the proteins characteristic of HIV those known as gp120 and gp24 (Science 253, 1138; 6 September 1991).

But how can a mouse develop antibodies against protein constituents of a virus of which it is apparently innocent? The authors' explanation is embodied in a theory put forward before the experiments were done (Hoffmann et al., Proc. Natn. Acad. Sci. U.S.A. 88, 3060; April 1991). Briefly, it is that AIDS is an essentially auto-immune disease in which T cells have lost the normal 'anti-self' interdiction, but instead kill each other. The viral coatprotein gp120 is concerned because, Kion and Hoffmann argue, it is likely to bear a close structural similarity to class-II MHC proteins (where MHC means 'major histocompatibility complex').

The other piece of evidence (to be published as Scientific Correspondence in Nature next week) is an account of observations on the protection of macaque monkeys against the simian analogue of HIV called SIV (simian immunodeficiency virus) by means of a vaccine consisting of monkey T cells first infected with SIV and then inactivated. The group concerned is at the National Institute for Biological Standards and Control in Hertfordshire. E. J. Stott and eight colleagues describe how they immunized a group of four macaques with their inactivated cellular vaccine, and four others with identical cells that had not been infected with SIV.

That three animals in the first group were protected against later challenge with SIV would have been good news for the vaccine-makers. The first surprise is that two out of the control group of four were also protected. And the sensation is that the essential difference between the protected and unprotected monkeys is that the former have ten times as much antibody against components of the $T$ cells used as virus carriers as do the latter - the control group susceptible to SIV infection on later challenge (see story page 287 ).

Again, it seems, the presence (or absence) of SIV is not the sole determinant of the production of antibodies apparently diagnostic of vulnerability to infection. (In these experiments, antibodies against the protein components of SIV have been looked for, but have not been found.) Hunting through past records has allowed the group to extend its suspicions to vaccines based on purified (and then inactivated) SIV particles as well as to another culture of T cells; again it seems (with 40 animals) that the distinctive diagnostic of protection against later challenge with SIV is the level of antibody against the T cells from which the vaccine was derived.

It goes without saying that the British results would have been even more persuasive that something strange is afoot if the vaccination experiments had more often been accompanied by adequate control groups. It is not so much that monkeys are scarce, but that the general inhibition of their use has persuaded people that corners should be cut. The result may well be that an important qualification - to say the least of it - of the standard picture of AIDS infection may have been needlessly delayed.

The idea that the mechanism of AIDS may be that of an auto-immune disease helps to explain some of the special features of AIDS, of which the usually long interval between infection (with HIV) and the emergence of the eventually fatal symptoms are two. Another is Duesberg's main plank in his campaign against the conventional wisdom: that virus can be recovered from only a small proportion, perhaps 1 in 500 , of the T cells in a person infected with HIV; how, he asks, can that be reconciled with the view that the depletion of $T$ cells is caused by the multiplication of virus in infected cells and their spread to others?

Hoffman's theory is more specific. The starting point is the mechanism of selftolerance in which $\mathrm{T}$ cells are selected in the thymus not to react strongly against an organism's own MHC molecules. What happens, then, when foreign lymphocytes find their way into a person's blood? The immune system will make antibodies against the recognizable antigens on the surfaces of the cells, and T cells will be organized to kill off the intruders. But then suppose that HIV is simultaneously injected into the blood; the immune system will similarly dispose itself against that foreign material. But if the cunning of HIV is that gp120 closely resembles the standard structure of class-II MHC molecules, there will then be two armies of T cells organized to attack each other.

That, at least, is a simplified form of what Hoffmann says. In reality, there are several different kinds of $T$ cells, the interaction between them is a dynamic process and the most that can be said is that, after a simultaneous exposure of a person's immune system to both foreign lymphocytes and HIV, the usually delicate dynamic balance between cells with different functions and specificity is undermined.

It would be wrong to suppose that this is what really happens in the course of AIDS. (Recent studies suggest that gp 120 and MHC class II bind to different sites on the CD4 molecule, the receptor for gp 120: Fleury et al., Cell 66, 1037; 1991.) But one of Hoffmann's more recent observations may carry weight; mice bred for autoimmune disease (and used as models for lupus) turn out spontaneously to make antibodies that react with gp120 even though they have never been exposed to HIV. The British observations (small though the numbers are) are then complementary; an immune response against foreign cells protects against infection with SIV.

Until confirmed (or otherwise), these developments must cause heart-searching throughout the world's programmes of AIDS research. People will be wondering whether the search for a vaccine against HIV should be replaced by programmes to induce tolerance of its protein components. The hunt for mechanisms of the adventitious infections characteristic of AIDS and of Kaposi's sarcoma will be given pause. Even the epidemiologists would be set back on their tracks.

None of this would imply that HIV is irrelevant to AIDS, but that an immune response to foreign cells, most probably lymphocytes, is also necessary. Duesberg will be saying, "I told you so".

John Maddox 